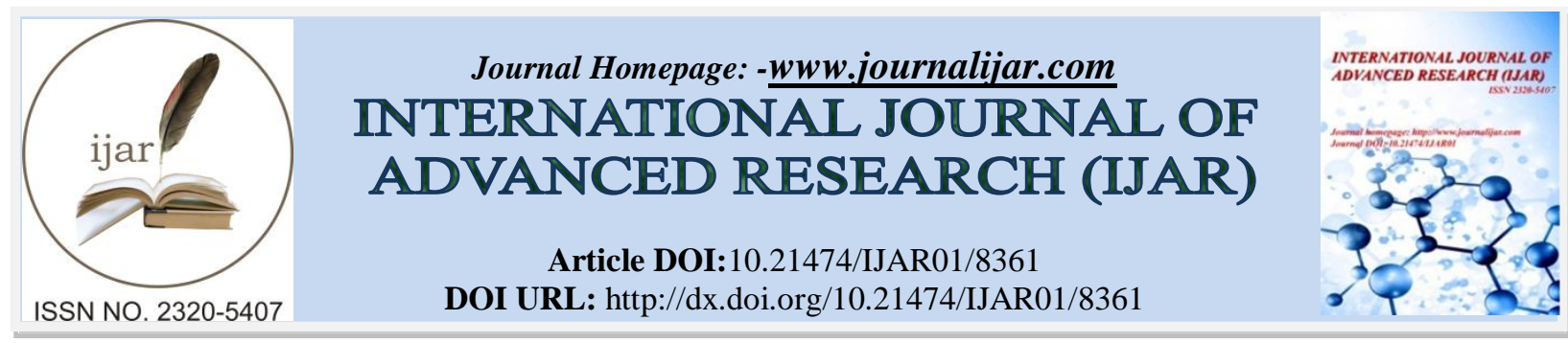

RESEARCH ARTICLE

\title{
PEDAGOGICAL PRAXIS OF MILLENNIAL TEACHERS IN MAINSTREAMED PHYSICAL EDUCATION.
}

Jem Cloyd M. Tanucan, LPT, MAEd.

Student Teaching Mentor, College of Teacher Education Cebu Normal University, Cebu City, Philippines, 6000

\section{Manuscript Info}

Manuscript History

Received: 08 November 2018

Final Accepted: 10 December 2018

Published: January 2019

Key words:-

Asia, Inclusive Education,

Mainstreaming, Millennial,

Phenomenology, Physical Education, Philippines.

\section{Abstract}

Whereas the motto of the United Nations' 2030 Agenda for Sustainable Development is "Leave no one behind", it serves as a guiding principle for all to work towards an inclusive society. As Physical Education (PE) serves as a fertile ground for expressions of supportive milieu, the new generation of PE teachers should seize this opportunity to become advocates of mainstreaming students with additional needs in order to achieve substantive equality for all in schools. Pursuing this endeavor, understanding the meaning of their experiences in mainstreaming may give a glimpse of the current perspectives and viewpoints that are vital in the formulation of appropriate intervention for improved inclusive instruction in the 21st century. This Heideggerian phenomenological study using one-on-one unstructured interviews was used to explore the meaning of the lived experience of the seventeen (17) purposively selected millennial teachers in mainstreamed PE classrooms in Cebu City and Cebu Province, Philippines. Using hermeneutical analysis, it was deduced that while they see mainstreaming as a wonderful concept, their experiences on it had apparently captured A Reflection of a Wider Problem on Inclusion in Academia as an overarching theme that encapsulated how PE teachers today subsisted the multifaceted issues and challenges on mainstreaming. This journey was specified through the subthemes: A Test of Pedagogical Competence, Multifaceted Contextual Inclusion Challenges, Fete of Teacher's Complex Support Roles and Risk of Curriculum Infidelity. The findings implicate that pedagogies that "fit all" do not guarantee the best possible learning outcomes and, teachers who represent only as "teacher" do not foster inclusive ethos to their students. Achieving these expectations can be daunting, thus, it is recommended that education administrators to conduct capacity building opportunities to the faculty and staff for indepth theoretical knowledge and practical understanding on the concept and application of inclusive education.

Copy Right, IJAR, 2017,. All rights reserved.

Corresponding Author: - Jem Cloyd M. Tanucan.

Address:- College of Teacher Education Cebu Normal University, Cebu City, 6000, Philippines. 
The United Nations' 2030 Agenda for Sustainable Development is "Leave no one behind", represents an unprecedented opportunity to initiate and implement catalytic changes towards an inclusive society. This means that development cannot be considered successful unless it reaches everyone. Unlike from its predecessor, the Millennium Development Goals (MDGs) were silent on disability that consequently excluded persons with disabilities from many development initiatives of various organizations and institutions. As school enrolment today increased, they were largely left out of this achievement. To ensure inclusion-oriented development, it is important that the concept of inclusion should be visible in academic and scientific endeavor.

As Physical Education (PE) serves as a fertile ground for expressions of supportive milieu, the new generation of PE teachers should seize this opportunity to become advocates of mainstreaming Students With Additional Needs (SWANs) in order to achieve substantive equality for all in schools. PE is valuable for children in many ways, aside from the physical benefits it brings, children are taught about life skills that are vital in surviving in the complex diverse society. In this case, PE teachers hold a vital responsibility of developing healthy, physically literate and well-rounded children regardless of gender, religion, social status and abilities. Thus, the PE curriculum in schools should be recognized as a fertile ground for expressions of supportive environment that helps the fight against social exclusion (Fernandes \& Müller, 2008). When all children, regardless of their differences, are educated together, it serves as the cornerstone of inclusive education where the principle of "mainstreaming" is applied. Mainstreaming is about the SWANs being taught full-time in a general education classroom by a regular education teacher. It creates a microcosm of the society, where children is interacting and collaborating with one another regardless of their differences. In this process, all children will benefit which include a more positive attitude to individuals with disability, improved social skills, and self-respect (Bekele, 2017). With this tenet, various laws and policies for inclusion have been introduced in Philippine Education system that heralded the call for PE teachers to strengthen and widen their share in educating all students with or without disability in school spaces. As mainstreaming of children with varying types of abilities in PE classes becomes more prevalent (Nadeau \& Tessier, 2007), it is also crucial that the experiences of those involved are explored. This research described the experiences of millennial teachers in mainstream PE classes. It is imperative to look into the perspective of the new generation such as the teachers themselves because by 2025 , they will comprise $75 \%$ of the workforce (Layton, 2015), covering one-third of global employees who will hold the greatest influence in shaping the future generations.

According to Svensson (2005), there is a low level of physical activity participation among children with physical disabilities. The same situation is experienced by children with intellectual disability as they often engaged in sedentary and other obesity related behaviors (Conod \& Servais, 2008). While inclusive PE is embraced at a conceptual level and desired at the classroom level, these types of students rarely participate in organized sport outside of school hours (Packer et al.,2006). Previous studies on inclusion have shown the complexity of successful implementation which oftentimes overlooked the policy and curriculum guidelines. With the concept of inclusivity in instruction as emphasized by of Haegele \& Sutherland (2015) and Healy, Msetfi, \& Gallagher (2013), it is very important to consider the appropriateness of implementation as it can lead to SWANs being isolated or made fun of when an inclusive environment is poorly conceptualized. This calls for PE teachers, specially the new ones, to cater these students with proper care and support. Bukvić (2014) indicated that a successful inclusive classroom should involve a teacher who has a developed personal competencies to create a stimulating and accommodating environment for learning. But the issue on millennial generation pivots on their work behaviours. According to Pierce (2015), they are lazy and ignorant of the way the world works. They are also entitled, arrogant, self-absorbed, undependable, and lacking a strong work ethic as described by Hartman (2014). The complexity of mainstreaming demands competences that can deal with students' varying learning, emotional and behavioural characteristics. With the consideration that teachers' attitudes on inclusion and their everyday philosophies on teaching (Green, 2002) have a considerable impact on the success of educational outcomes, understanding the meaning of the experiences of the millennial teachers may give a glimpse of the current perspectives and viewpoints that are vital in the formulation of appropriate intervention for improved inclusive instruction, and in devising future policy in relation to supporting teachers in their quest of giving quality PE for all.

Imbued with the above premise, it is imperative this study was made to explore the experiences of millennial teachers as they make sense of their pedagogical praxis in mainstream PE curriculum. The application of Heideggerian phenomenology answered the question: What are the lived-experiences of the millennial teachers in mainstreamed physical education? As phenomenology describes and interprets the shared practices and common meanings of experiences (Benner, 1994), it also attempts to address the situatedness of individual's dasein (the human way of being in the world) in relation to various contexts that complements the formulation of the meaning 
of experiences (Campbell, 2001). Therefore, this study has highlighted the concept of forestructure of understanding where the researcher and the informants cogenerate an interpretation of the phenomenon being studied.

\section{Philosophical Stance:}

This study is situated within the constructivist paradigm (Mertens, 2005; Creswell, 2014) where meanings of the lived experience of the phenomenon are constructed within the viewpoints of the informants and the researchers. This stance considers knowledge as a social construct, attempting to understand the complexities of multiple realities through the iterated interaction and interpretation of the researcher and informants or otherwise known as relativist ontology (Mertens, 2005; O’Leary, 2004 and Flick, 2009). Therefore, the researcher believes that meanings of experience depends significantly upon the ability to get in touch into the world or experience as it is constructed by the informants.

\section{Methodology:-}

At the core foundation of qualitative research are individuals' stories, behaviors and perspectives. Hence, the researcher being the main instrument of the study is not only to listen and record others' voices, but to analyze their statements into meanings of their context. With this objective, Heidegger's interpretive phenomenology is the appropriate design. This study has interviewed seventeen (17) purposively selected PE teachers from different public schools in Cebu City and Cebu Province, Philippines in order to capture the entirety of meanings behind their experiences in mainstream PE classes. Informants were selected through the three criteria: (1) Basic Education PE teacher who experience mainstreaming in PE classroom, (2) with less than three years of experience in teaching and 3) born from 1981 to 1996 . The collection of data was finally adjourned after data saturation was achieved. The use of unstructured interviews was done to have a smooth flow of conversation between the participant and researcher. All the significant data were analyzed using hermeneutical analysis as described by Smith, Flowers, and Larkin (2009). Specifically, the researcher followed a four-part analytical process: (1) reading and re-reading; (2) initial noting; (3) developing emergent themes; and (4) searching for connections across emergent themes.

\section{Trustworthiness:}

1. Credibility of this study was upheld by securing prolonged engagement with the informants as the interview process occur within an average of 30 minutes. With this timeframe, the researcher was able to reveal conceptual story that represents the essences of the experience under investigation. Also, validating the research findings by sharing to informants the completed research paper has strengthened the confidence of the truth in the data, thereby ensuring accurateness and correctness as they were transcribed and interpreted.

2. Dependability was established through the constant reviews of the methodologies and findings by social research experts to preserve maximum precision of data gathering, transcriptions and analysis.

3. Confirmability was applied by adhering data saturation to ensure that adequate and quality data are collected from sufficient number of informants to support the study. Member checking and data triangulation of the formulated accounts were done to minimized bias and achieve neutrality.

4. Transferability was considered by adequately providing the descriptions of the research design, the informant's characteristics, methodology and results in order for the future researchers to determine the practical application of this research to another setting.

\section{Ethical Consideration:}

Due to the nature of this research in which the researcher may dwell into the personal domains of the teachers during the interactive sharing on their experience in mainstreamed PE, it is critical to clearly observe several ethical considerations to ensure that the content and method of asking do not divert to the objective stipulated in this paper. Hence, the researcher has observed cautious actions by means of adhering informed consent from the informants before data collection process had occurred. Specifically, the principles of voluntary participation, the provisions of harm/risk, honesty and trust, privacy, confidentiality, and anonymity were followed. Moreover, all information whether written, computer generated and audio and/or visually recorded were destroyed at the end of the study as requested by the informants to protect their privacy and preserved their anonymity.

\section{Results and Discussion:-}




\section{A Test of Pedagogical Competence:}

The data from the interviews showed that teachers perceived their PE teaching experience in mainstream classrooms as a test of their pedagogical competence. These experiences were manifested as they expressed that "the experience has tested the learnings they have acquired in their education courses specially in catering unique individual needs of their students". Although they held a favorable predisposition to mainstreaming, the wide ability range of SWANs had compelled them to deconstruct classic, traditional instructions designed for regular students to a reconceptualize pedagogic praxis that fits appropriately to these type of students. Their experience had made them reflect as well how strong and sufficient their acquired competencies are vis-à-vis creating individualized PE learning opportunities. They reported specifically that their educational foundation in adapted PE courses is very limited that most of what they have learned is very difficult to implement in real life setting.

\section{Informant 2:}

"The things I have learned from adapted PE class is not enough to answer the needs of my students who have additional/special needs. It is also very difficult to attend to their needs individually."

\section{Informant 6:}

"My experience in a mainstreamed PE classroom is like the concept of expectation versus reality. I expected that it is easy to handle PE classes to SWANS as we were taught the course adapted PE in our undergraduate years. However, in reality, it does not go that way. It is very difficult and challenging since you have cater all of your students with or without disability to play and engage in any activities."

Their experiences is coherent to the study of Smith and Thomas (2006) which proved that even if teachers support the inclusion philosophy, there is still a general feeling that achieving full inclusion in schools is impossible. The culprit is the narrow ability of teachers to provide the best support to children with additional needs, despite wanting to be able to help them. Teachers need specific knowledge and skills that promote pedagogical and educational practice. Although all the informants indicated that they get training in an academic context, they did not have strong and specific training in the professional context. With respect to the results of this study, millennial teachers do not come to the classroom with a complete knowledge and understanding of disabilities or disorders. If, in the classroom with students of such issues, the job of teaching becomes potentially unsatisfying. With this situation, there are manifestations of reluctance among the teachers in including the SWANs in a proper way. Hence, it is necessary to understand the ways in which teachers in the millennial generation perceive not only inclusion, but the ways in which their training prepares them to teach in inclusive environments.

\section{Multifaceted Contextual Inclusion Challenges:}

Inaccessible Inclusion Space and Materials. The cornerstone of full inclusion has always been on educational equity. It means that education itself provides all children an access to a wide range of learning opportunities, tools, and environments needed to be successful in academia and in life. However, based on the findings of the study, none of the seventeen (17) public schools that mainstreamed SWANs have available resources and materials that are useable and accessible for these students. Students learn better when they see themselves situated in the curriculum spaces, when they feel "included" in school by means of providing curb cuts, ramps, and facilities designed for them. But, this research has provided information that many public schools are not ready for inclusion. What happens is that the problem with regard to the scarcity of PE facilities and equipment has worsened by the fact that there are also no available PE tools nor spaces that accommodates the unique needs of the SWANs. As indicated by:

\section{Informant 2:}

"The absence of the materials that assist the SWANs has made it very difficult for me to effectively give the quality PE that my students should experience."

\section{Informant 10:-}

"The things I have learned from adapted PE class is not enough to answer the varied needs of my students who have additional/special needs. More so, even if I had create individualized instructions for them, the problem now are the materials in PE which most of the schools do not have enough."

Informants of this study were unanimous in pointing out that teaching SWANs can be exasperating and discouraging when there is meagreness or absence of appropriate technical and physical facilities in the class. This observation is similar to the study to Rimmer \& Rowland (2008) that reported the lack accessibility of fitness facilities and other 
games and sports spaces delimit the participation of individuals with physical disabilities that consequently positioned them to have a greater risk of chronic as compared to the general population as indicated by Centers for Disease Control and Prevention ("Disability and Health," 2018). In the Philippines, a study commissioned by Disability Rights Promotion International (DRPI) and the National Federation of Organizations of people with disabilities in the Philippines (Katipunan ng Maykapansanan sa Pilipinas, Inc., KAMPI) in 2008, found that people with disabilities often experienced barriers to social participation and access to health and rehabilitation in both in educational and employment settings.

Classroom Teachers' Dilemma. All informants agreed that the greatest share of the burden of mainstreaming falls upon the insufficient training of the teachers to be able to effectively carry out the task they are responsible to do. For one teacher who potentially has more than 30 students in each of five to seven classes, when students are grouped according to educational needs, added with another groups of students who have varying special needs, the task can be daunting. Inclusive classrooms definitely require a lot of training on the part of teachers, however the results of this study have shown otherwise since majority do not receive sufficient training on inclusion or seminars related to teaching SWANs in mainstreamed classrooms. What happens in the PE classroom is that SWANs ended up being the "assistants" of teachers in recording, organizing and simple task not related to the competency being taught.

\section{Informant 9:}

"I never had given the chance to participate in any training about inclusion. That is why whenever I handle PE classes with SWANs, I always ask them to assist me in collecting notes, checking attendance and recording scores."

\section{Informant 14:}

"In my 6 years of teaching, I never had a chance to attend trainings that capacitates me to adapt lessons fit for students with disability."

The informants reported that since many of these students require a high degree of physical care and management over and above their special educational needs it is essential to understand the concept of individualized instruction. But only few have the confidence to realize the concept. This is the same to the study of Zulfija et. al (2013) and Thwala (2015) and as they discussed lack of competence of the teachers to include students with disabilities into their classes. Adaptive instruction would not become a problem if teachers have the sufficient amount of knowledge and skills in creating lessons for various special needs of the students. With the informants' responses, it has been known that access to prior training for teachers is either non-existent or sporadic. The lack of sufficient educational training of teachers is seen as a significant weakness in the individualizing instruction. Professional development, support and training in addition to adequate funding are urgently needed.

With the respect of the results in this study, the current scenario of children with disability in the public school is clearly a violation of their rights. The Philippine Constitution of 1987 reflects the educational provisions which calls for encouragement of non-formal, informal and indigenous learning system, as well as self-learning, independent and out-of-school study programs, and to provide the disabled with training on civics, vocational efficiency and other skills. Students with learning disabilities require adapted instructions that meet their specific learning needs. When a PE teacher has neither the training nor the flexible time to provide this type of instruction, this can lead to the child not progressing with skills or may cause adverse medical incidents. The need to provide quality education to the children with disabilities and take a sense of urgency as evidenced indicated in this study.

\section{Fete of Teacher's Complex Support Roles:}

SWANs often become frustrated because they see themselves as being incompetent in many areas of school, thus generally making them unmotivated and unexcited to complete tasks out of fear, embarrassment, and disrespect. The study conducted by Irvin, Meltzer, \& Dukes (2007) reported that in order for students with disability become more engaged and motivated in academics, the teacher should be able provide learning opportunities that improve their competence in accomplishing specific tasks. Hence, teacher's complex support role is needed to foster that motivation.

Teacher as a Parent. For schools to be a positive experience for children, there has to be congruence between the children's experiences at home and at school. Some teachers have articulated their experience to be equated to the role of a parent. In the present study, a teacher who is nurturing and providing were the most recurrent description of 
their role in a mainstream PE classes. This reveals that the learners perceived their PE teachers similar to a parent who provides not only fundamental knowledge but also a sense of comfort and security.

\section{Informant 15:}

"Students with disability needs special attention and care that is why as a teacher I do not just see myself as a facilitator of learning but also a mother who is ready to give comfort whenever there are disappointments and as a father who ready to protect whenever there are mischiefs."

Teachers indicated that a school is similar to a home because just like parents, it is their responsibility to help their children (students) with whatever things they need. Perhaps for example in the article by Autism Ontario in 2011, Children with Autism should be given small rewards or are reinforced every time they give appropriate responses. These 'reinforcers' have to be based on a child's personal preferences in order to serve as an effective motivator. The use of rewards may lead to the development of the child's social, language and behavioral skills. In a logical sense, to effectively deal with SWANs, the teacher has to go beyond being a teacher to instigate real life things for them to feel free from any disability and to give encouraging words and advices just like parents.

Teachers as a Friend. In this study, teachers perceived their role as provider of support for SWANs. Such support describes specifically to a person who can give immediate "comfort" and "confidence whenever there is a need. Just like a friend, informants indicated that the professional boundaries required for a teacher to create a harmonious environment is no different from the requisites of a healthy friendship.

\section{Informant 1:}

"I believe that forging a genuine personal connection between me as a teacher and my student is fundamental to the success of mainstreamed PE classroom. For instance, the need to create a personalized or individualized the exercise program for students, requires me to connect with my students at personal level. I always try to engage discourses to them just like friends who share strengths, weaknesses, disappointments and experiences with each other."

The notion of a "teacher as friend" highlights the affective, personal and moral component of teaching which creates an educational environment that is not coercive. The millennial teachers who are socially active in nature deconstruct the meaning of professional distance, wherein a professional teacher concerns about giving caress to students in order to create a community-like environment in the classroom in any contexts and circumstance.

Teacher as a Mentor. Informants believe that teachers have great influence on the students. This influence involves activities such as learning, mentoring, coaching and other facets of student's lives. For instance, informant 3 assumed his responsibility as a mentor by guiding students through difficult decisions through offering sound advice. Because children with disabilities are oftentimes lonely and have fewer friends, Lindsay and McPherson (2012) quoted that these students in the field of sports or socio-cultural gathering are often left excluded. In Informant 9 words, "whenever there are dance activities, it makes me sad seeing students with disability often sit around the corner waiting for the PE time to end". That is why, off the field, teacher-informants tried their best to talk with these students, ask for their feelings or apprehensions with the activity and give some good advices for them to be cheered up. Oftentimes the sharing was about their frustrations on the things they wanted to do but they could not; physical activities like running, dancing and singing along with classmates without the problems of disability.

\section{Informant 8:}

"It breaks my heart whenever the SWANs share their frustrations to me, express their point of view and describe how they live as different from the normal others. So, being the teacher I give advices about happiness and living the life that the creator has given."

Millennial teachers believe that the mentoring-based relationships they shared with their students have given them more purpose than teaching, it is about touching lives. Informant 4 described the mentoring experience as catalyst of positive development for SWANs, that, because of his advices, he observes children become more open and sociable compared to when he was not given much time for mentoring. The study of Petitpas, et al. (2005) substantiated the same concept of mentoring in fostering positive youth development. Also, since SWANs often times experience social issues, there is a possibility that it can affect their self-concept, their view of the world around them (Pijl and 
Frostad, 2010), hence, mentoring experience is needed for them to feel assured, secured and comforted. Moreover Lindsay and McPherson (2012) indicated that teachers play a critical role in influencing the quality of social inclusion in the classroom as perceived by children with disability.

\section{Risk of Curriculum Infidelity:}

During the interviews, teachers expressed that mainstreaming of SWANs in their PE classes has challenged their competence on curriculum implementation for inclusive classroom. Hence, they adapt, alter, or reinvent programs fitted to the context of students. They expressed that meeting the needs of the students, their lack of proper training, school disruptions and lack of facilities for both students with and without disability have challenged them to implement the competencies in the curriculum as stated.

\section{Informant 1:}

"I am guilty that sometimes I just let my students (with disability) to just observe the dance activity as they might have hard time catching up with their peers."

\section{Informant 8:}

"There are times that I just gave them (SWANs) other task like article critique instead of playing sports with their classmates. This is to protect them from any harm as they are vulnerable to injuries because of the bellicose nature of sports and their condition."

Because majority of the teachers do not have the sufficient knowledge and training to carry out physical activities without compromising the competencies in the curriculum, this results to exclusion of students in the learning opportunities that PE can offer. As the curriculum policy requires teachers to implement the highest possible quality, as such it is believed that competencies or standards should be delivered in the exact way they were developed and tested, any bargaining will most likely decrease the effectiveness of the program (Elliot \& Mihalic, 2004). However, the context of curriculum adaptation is often debated (Chiodo, 2017). According to McCuaig \& Hay (2014), the concept of alterations in the curriculum are necessary to fit to the local context in which they are implemented. The emphasis on strict fidelity therefore should conform the teacher's ability to adapt the program appropriate for changing classroom circumstances and diverse students (Kutcher \& Wei, 2013). But in this study, the tenets of adaptation is often abandoned leading to exclusion practices of SWANs. Thus, program implementation is highly dependent upon the belief of the individuals who are expected to deliver the implementation.

The findings of this hermeneutic inquiry capture commonalities and ambiguities of the millennial teachers' experiences in a mainstream PE classrooms. After data analysis, four essential subthemes were identified through the seamless interaction and interpretation of the constructed reality between the researcher and informants. These subthemes are: (a) A Test of Pedagogical Competence, (b) Multifaceted Contextual Inclusion Challenges, (c) A Fete of Teacher's Complex Support Role, and (d) Risk of Curriculum Infidelity. Although these subthemes were fundamental to the meaning of mainstreaming in PE classroom for the millennial teachers, A Reflection of a Wider Problem on Inclusion in Academia, eventually emerged as the overarching theme that alluded the holistic constructed interpretation of the phenomenon understudied.

\section{A Reflection of a Wider Problem on Inclusion in Academia:}

The concepts of "disability" or "additional/special needs" in a classroom environment is an indication that students learn in different ways and so, education that "fits all" does not guarantee the best possible learning outcomes. It is only when the curriculum implementation is supported by the tenets of differentiated instruction that prepares the students for future success. While millennial teachers see mainstream classroom as a wonderful concept that promotes educational equity, their experiences on it had apparently captured A Reflection of a Wider Problem on Inclusion in Academia that illustrates how they subsisted the multifaceted issues and challenges on mainstreaming by reflectively recognizing their experience as A Test of Pedagogical Competence; vigorously engaging productive ways to neutralized Multifaceted Contextual Inclusion Challenges; compassionately representing Fete of Teacher's Complex Support Roles to alleviate social exclusion among SWANs and constantly reinventing programs to mitigate the Risk of Curriculum Infidelity.

\section{Conclusion and Recommendations:-}


The lived-experiences of the millennial teachers in mainstreamed physical education reflects a wider problem on inclusion in academia as they are being overwhelemed by multifaceted challenges and issues which percolate in the personal, professional, administrative and educational context. Also, their experiences correspondingly implicates that pedagogies that "fit all" do not guarantee the best possible learning outcomes and, teachers who represent only as "teacher" do not foster inclusive ethos to their students. Achieving these expectations can be daunting, thus, it is recommended for policy makers to craft a program that instigates rigorous analysis and research on mainstreaming and inclusion in the classroom, and for education administrators to conduct capacity building opportunities to the faculty and staff for in-depth theoretical knowledge and practical understanding on the concept and application of inclusive education in the 21 st century..

\section{Acknowledgement:-}

The author thanks the study informants for their contribution to the research and for the anonymous referees for their invaluable inputs.

\section{Conflict of interest statement:}

The author declares that the research will be conducted in the absence of any commercial or financial relationships that could be construed as a potential conflict of interest.

\section{References:-}

1. Benner, P. (1994). The tradition and skill of interpretive phenomenology in studying health, illness, and caring practices. In P. Benner, (Ed.), Interpretative phenomenology, embodiment, caring, and ethics in health and illness (pp. 99-127). Thousand Oaks, CA: Sage Publications. doi:10.4135/9781452204727.n6

2. Bekele B.A. (2017). Challenges and experiences on inclusive physical education: The case of Bahir Dar elementary schools. International Journal of Physical Education, Sports and Health 2017, Vol. 4(2), 94-99. Retrieved from http://www.kheljournal.com/archives/2017/vol4issue2/PartB/4-2-2-134.pdf

3. Bukvić, Z. (2014). Teachers' competency for inclusive education. The European Journal of Social and Behavioural Sciences, Vol. 2 (3), 1585 - 1590. http://dx.doi.org/10.15405/ejsbs.141

4. Campbell, R. (2001). Heidegger:Truth as Aletheia. In R. Small (Ed.), A hundred years of phenomenology: Perspectives on a philosophical tradition. Burlington, VT: Ashgate.

5. Chiodo, D. G. (2017). A qualitative study of the fidelity of implementation of an evidence-based healthy relationships program. Electronic Thesis and Dissertation Repository. 4405. https://ir.lib.uwo.ca/etd/4405

6. Conod L \& Sarvais L (2008). Sexual life in subjects with intellectual disability. Salud Pública de México, Vol. 50, 230-8. Retrieved from https://scielosp.org/pdf/spm/2008.v50suppl2/s230-s238/en

7. Creswell, J. W. (2014). Research design: Qualitative, quantitative, and mixed methods approaches. 4th Ed. London: Sage

8. Crotty M (2003). The Foundations of Social Research: Meaning and Perspective In The Research Process. Sage, London Disability and Health (2018, August 24) Retrieved from https://www.cdc.gov/ncbddd/disabilityandhealth/relatedconditions.html

9. Elliott, D. S., \& Mihalic, S. (2004). Issues in disseminating and replicating effective Prevention programs.Prevention Science, Vol. 5(1), 47-53. Retrieved from https://link.springer.com/article/10.1023/B:PREV.0000013981.28071.52

10. Fernandes, L. P. ; Müller, V. R. (2009). Exclusão e inclusão social: contribuições e Experiências inclusivas na educação física. Retrieved from http://www.diaadiaeducacao.pr.gov.br/portals/pde/ arquivos/949-4.pdf. Retrieved on August 12, 2018.

11. Flick, U., 2009. An Introduction to Qualitative Research. 4th ed. London: Sage.

12. Green, K. (2002). Physical education teachers in their figurations: a sociological analysis Of everyday 'philosophies.Sport, Education and Society Vol. 7(1), 65-83. https://doi.org/10.1080/13573320120113585

13. Guba, E. G., \& Lincoln, Y. S. (1994). Competing Paradigms in Qualitative Research. In N. K. Denzin \& Y.S. Lincoln (Eds.), Handbook of Qualitative Research (pp. 105-117). Thousand Oaks, CA: Sage.

14. Justin A. Haegele \& Sue Sutherland (2015). Perspectives of students with disabilities toward Physical education: A Qualitative Inquiry Review.Quest, Vol. 67 (3), 255-273, DOI: 10.1080/00336297.2015.1050118

15. Hartman, M. (2014, March 24). Millennials at work: young and callow, like their parents. The New York Times. Retrieved from https:/www.nytimes.com/2014/03/25/your-money/millennials-at-work-young-and-callow-liketheir-parents.html 
16. Healy, S., Msetfi, R., \& Gallagher, S. (2013). Happy and a bit nervous": the experiences Of children with autism in physical education.British Journal of Learning Disabilities, Vol. 41(3), 222-228. doi: $10.1111 /$ bld.12053

17. Irvin, J. L., Meltzer, J., \& Dukes, M. S. (2007). Taking Action on Adolescent Literacy: An Implementation Guide for School Leaders. Alexandria, VA: Association for Supervision and Curriculum Development.

18. Jandayan M, Figueroa SR, Canales D. (2009). Monitoring the human rights of persons with disabilities: Preliminary report - Philippines. Manila: Katipunan ng Maykapansanan sa Pilipinas, Inc. (KAMPI) and Disability Rights Promotion International (DRPI)

19. Kutcher, S., \& Wei, Y. (2013). Challenges and solutions in the implementation of the school Based pathway to care model: the lessons learn from Nova Scotia and beyond. Canadian Journal of School Psychology, Vol. 28(1), 90-102. DOI: 10.1177/0829573512468859

20. Layton, D. L. (2015). Perceptions of Millennial Teachers' Commitment to Teaching as a Career. Theses and Dissertations. 1202. http://scholarworks.uark.edu/etd/1202

21. Lindsay S, McPherson AC. (2012). Experiences of social exclusion and bullying at school Among children and youth with cerebral palsy, Disability and Rehabilitation Vol. 34, 101-109. doi:10.3109/09638288.2011.587086.

22. Mertens, D. M. (2005). Research and Evaluation in Education and Psychology: Integrating Diversity with Quantitative, Qualitative, and Mixed Methods (2 Ed.): Thousand Oaks, CA: SAGE Publications

23. Louise McCuaig \& Peter J. Hay (2014). Towards an understanding of fidelity within the context of schoolbased health education. Critical Public Health, Vol. 24 (2), 143-158. DOI: 10.1080/09581596.2013.840718

24. Nadeau, L., \& Tessier, R. (2007). Social adjustment of children with cerebral palsy in Mainstream classes: peer perception. Developmental Medicine \& Child Neurology, Vol. $48 \quad$ (5), 331-336. https://doi.org/10.1017/S0012162206000739

25. O'Leary, Z. (2014). The essential guide to doing research. London, UK: SAGE Packer, T.L., Briffa, T., Downs, J., Ciccarelli, M., and Passmore, A. (2006). The Physical Activity

26. Study of Children and Adolescents with a Disability. Curtin University of Technology.Retrieved from https://espace.curtin.edu.au/bitstream/handle/20.500.11937/31040/19696_downloaded_stream_214.pdf?sequenc $\mathrm{e}=2$ \&isAllowed $=\mathrm{y}$

27. Petitpas, A. J., Cornelius, A. F ., Van R, J.L,\&Jones,T.(2005).A framework for planning youth sport programs that foster psychosocial development. The Sport Psychologist, Vol.19, 63-80 Retrieved from https://static1.squarespace.com/static/5817757515d5dbcebad2b0bc/t/5964c559e4fcb58b9fb3d038/14997763463 43/05_JVRAP_frameworkforplanningyouth+-+link+community+pdf.pdf

28. Pijl, S. J., \& Frostad, P. (2010). Peer acceptance and self-concept of students with Disabilities in regular education. European Journal of Special Needs Education, Vol. 25 (1), 93-105. DOI: $10.1080 / 08856250903450947$

29. Rimmer J., Rowland J. (2008). Physical activity for youth with disabilities: a critical need In an underserved population. Developmental Neurorehabilitation, $\quad$ Vol. $\quad 11(2), \quad 141-148$. https://doi.org/10.1080/17518420701688649

30. Andrew Smith \& Nigel Thomas (2006) Including pupils with special educational needs and disabilities in National Curriculum Physical Education: a brief review. European Journal of Special Needs Education, Vol. 21(1), 69-83, DOI: 10.1080/08856250500491849

31. Smith, J.A., Flowers, P. \& Larkin, M. (2009). Interpretative Phenomenological Analysis. London: Sage.

32. Svensson L (2005). Physical Activity in Children with Physical Disabilities: Factors Influencing Participation and Functional Outcomes of Participation. Master of Philosophy (Thesis), Schools of Medicine and Human Movement Studies, The University of Queensland, Brisbane.

33. Thwala, S. (2015). Challenges encountered by teachers in managing inclusive classrooms in Swaziland. Mediterranean Journal of Social Sciences, Vol. 6(1), 495. Retrieved from http://www.mcser.org/journal/index.php/mjss/article/view/5489

34. Zulfija, M., Indira, O. and Elmira U. (2013). The professional competence of teachers in

35. Inclusive education.Procedia-social and behavioral sciences, Vol. $89 \quad(2)$, $549-554$. https://doi.org/10.1016/j.sbspro.2013.08.892. 